\title{
Blinded Me with Science: Motifs of Observation and Temporality in Lacan and Luhmann
}

\section{Jonathan Elmer}

T $\mathrm{n}$ taking up the topic of cybernetics in 1955, a field then exlerting influence on everything from telecommunications to public health management (see Heims), Jacques Lacan proposed the rubric of "conjectural sciences" for all those sciences of combination, where "[w]hat's at issue is the place, and what does or doesn't come to fill it, something then which is strictly equivalent to its own inexistence" (Seminar, Book II 299). This "science of the combination of places as such" is, to be sure, distinct from the exact sciences, which always focus on "what is found at the same place" (299). The exact sciences, in other words, deal with positivities, the conjectural sciences with probabilities. It is, indeed, to Pascal's arithmetic triangle that Lacan turns when he wishes to trace the origins of this science of combinations: "If this is how we locate cybernetics, we will easily find it ancestors, Condorcet, for instance, with his theory of votes and coalitions, of parties, as he says, and further back again Pascal, who would be its father, and its true point of origin" (296).

Several years earlier, in Cybernetics (a book with which Lacan

수 1995 by Cultural Critique. Spring $1995.0882-4371 / 95 / \$ 5.00$. 
was familiar) mathematician Norbert Wiener had also reached back to the 17th century in tracing the genealogy of cybernetics:

\begin{abstract}
If I had to choose a patron saint for cybernetics out of the history of science, I should have to choose Leibniz. The philosophy of Leibniz centers about two closely related conceptsthat of a universal symbolism and that of a calculus of reasoning. From these are descended the mathematical notation and the symbolic logic of the present day. ... Indeed, Leibniz, like his predecessor Pascal, was interested in the construction of computing machines in the metal. It is therefore not in the least surprising that the same intellectual impulse which has led to the development of mathematical logic has at the same time led to the ideal or actual mechanization of processes of thought. (12)
\end{abstract}

For Wiener, the development of cybernetics is a story of the power of formal and mathematical reason to introduce order and prediction into phenomena that do not behave in accord with Newtonian mechanics and temporality, that are not, as Lacan would say, ultimately always only where they are, "found at the same place" (Wiener 30-44). Lacan would agree with Wiener that the two sciences "are inseparable from one another" (Seminar, Book II 296) insofar as both rely on "the little letters" or pure signifiers which constitute an "ordered register" (299) of signification-the symbolic-that exists independently from, but renders cognitively accessible, the real.

But Lacan is, not surprisingly, more interested finally in the differences between conjectural and exact sciences. The central difference turns on the object of the inquiry, rather than the method: as his allusion to Condorcet's theory of votes and coalitions indicates, the conjectural sciences are fundamentally concerned with man-indeed, the rubric itself is meant to substitute for the "group of sciences normally designated by the term human sciences" (296). In this science of combinations, what "does or doesn't come to fill" its place is, at bottom, the human being, in all its various social and psychological itineraries. The terminological shift from "human science" to "conjectural science" would seem a purposive turn away from the subjective fascinations with human individuality: in making human beings subordinate to the "place" 
they either do or do not come to fill, the conjectural sciences make man appear always under erasure, as it were, alternately materializing and dematerializing, "strictly equivalent to [his] own inexistence" (299).

The importance of what Lacan thus characterizes as the "conjectural sciences" in the development of the social sciences can hardly be denied. Ian Hacking's The Taming of Chance, for example, demonstrates the crucial role, beginning in the 18th century, of probability and statistics in the management of social life. ${ }^{1}$ In a slightly different register, Christopher Herbert has rooted the "ethnographic imagination" in a readiness to conceive of social reality as essentially relational, a matter less of positive entities, be they individuals or classes, than of combinations and patterns: what he calls the "culture concept," a "need to think of culture (in the sense of a complex whole) as the composite of relationships existing among the phenomena of a given society" that goes back at least to the 18th century (10). Herbert provides a very interesting account of the transition from moral philosophy to political economy, as exemplified in the career of Adam Smith. What makes this transition so fluid is that both moral philosophy and political economy are essentially what Lacan calls "sciences of the combinations of the scanned encounter" (Seminar, Book II 300): that is, whether they deal with the complex sources of envy or deference, or the mysterious beneficence of economic competition, both inquiries extrapolate from an intersubjective matrix in which every calculation must include within it the potential calculations of others. Thus it is that attempts by the social sciences to move beyond the dimension of the merely subjective or intersubjective seem nonetheless to recur, intentionally or not, to the language and imagery of the human encounter: will the other show up or not? Lacan touches on this almost uncanny aspect of "man's waiting": "In the game of chance ... [man] has the idea that something is revealed there, which belongs to him, and, I would say, all the more so given that no one is confronting him" (300). The conjectural sciences emerge as the precipitate from a waiting game.

Sociologist Niklas Luhmann would describe the emergence of conjectural sciences out of the paradigm of the intersubjective encounter as the evolutionary drift of functional differentiation and, more specifically, as the differentiation of social systems 
and interaction systems. Sometime in the second half of the 18th century, it no longer became possible to understand society as "interaction," as essentially a series of face-to-face encounters. Competition for Luhmann, to take a prominent example, "is a non-interactional way of relating to others" ("Evolutionary Differentiation" 118); that is, it expresses the idea that social relations continue to operate even without the immediate presence of others, and hence without all the codified gestures of politesse and deference such presence normally requires. The economy becomes less "dependent upon rules of interaction," requiring instead an "understanding of [its] own structural conditions" (117). Economic thought becomes an abstract tracing of the movement of probable combinations. At the same time, however, this evolution toward a "structural understanding" of society was intimately linked to the vicissitudes of face-to-face "interaction": throughout the 17th and 18 th centuries a "new intensity of social reflexivity can be observed, of "taking the role of the other" (121). In this way, the "interaction system develops a combinatorial space of immense complexity," which itself requires, as it were, the introduction of noninteractional rules-"structural conditions"-to be managed. It is because "no participant can know the state of a 'simple' two-person interaction system" (121), because of the phenomenological impasse of what Luhmann calls, following Parsons, "double contingency" (a phenomenon best exemplified historically by the endlessly selfdefeating teaching of "sincerity" in 18th-century moral discourse) that interaction leads to, as its own surpassing or negation, a structural understanding of society. As Luhmann remarks, " $[\mathrm{t}] \mathrm{he}$ awareness of double contingencies autocatalyzes the development of social systems" (121). Social science, then, whether one understands it as the elaboration of "conjectural sciences" or as the result of the differentiation between society and interaction, finds itself, both historically and conceptually, in a kind of antagonism with a subjective or intersubjective substrate.

This antagonism-or more gently, and less anthropomorphically, this oscillation-between a formalized "structural understanding" of the social and its subjective or intersubjective substrate received its most thoroughgoing consideration 30 years ago, in Michel Foucault's The Order of Things. While acknowledging the "double advance" of modern thought, "on the one hand towards 
formalism in thought and on the other towards the discovery of the unconscious-towards Russell and Freud" (or towards Wiener and Lacan, we might add), Foucault also insists on a kind of internal asymmetry to this coupling, an asymmetry glossed over in Lacan's and Wiener's genealogies. For although formalization as an ideal and a method may well link figures like Russell and Leibniz, any consideration of their respective thinking about man is fundamentally skewed, suggests Foucault, if it does not recognize the appearance of the "positivity" of man toward the start of the 19th century. Thus, even if it is "of interest historically to know how Condorcet was able to apply the calculation of probabilities to politics" or "how contemporary psychologists make use of information theory in order to understand the phenomena of learning," such accounts of the thinking about man and his behavior must be tied to the historical recognition that the very appearance of man as an object of inquiry was made possible not by the extension but rather the "retreat of the mathesis" (Foucault 349). Rather than imagine a mere continuity with the Leibnizian project of a universal symbolic language, Foucault suggests we view the human sciences as bounded on one surface only by the project of formalization. The human sciences do, indeed, "have the more or less deferred, but constant, aim of giving themselves, or in any case of utilizing . . . a mathematical formalization." But they also touch on another edge the great empirical sciences Foucault unearths archaeologically: "they proceed in accordance with models and concepts borrowed from biology, economics, the sciences of language" (347). Most importantly, however, the human sciences share a third surface with a philosophical problematic of finitude inasmuch as "they address themselves to that being of man which philosophy is attempting to conceive at the level of radical finitude" (347).

It is this last element in Foucault's extraordinarily intricate archaeology of the human sciences that may be said to be privileged in Foucault's own account. "Modern man . . . is possible only as a figuration of finitude. Modern culture can conceive of man because it conceives of the finite on the basis of itself" (318). What this means is that "man," as an object of inquiry, as an epistemological "positivity," first becomes visible as limited, contingent, and partial. To be sure, there was thinking about human beings in ear- 
lier epochs, and there was a kind of Olympian vantage assumed by the Classical episteme, a vantage from which all might be surveyed in representation, but that vantage was not theorized as the particular property of man. Indeed, man's very identity, the very thought of his specificity, only emerges, argues Foucault, out of a shift to what we would now call-after Saussure's signifiers have made it so famous - a regime of pure differentiality:

It is apparent how modern reflection, as soon as the first shoot of this analytic [of finitude] appears, by-passes the display of representation, together with its culmination in the form of a table as ordered by Classical knowledge, and moves towards a certain thought of the Same-in which Difference is the Same thing as Identity. (315)

Man, and with him the human sciences, emerges not as the peak of a pyramidal hierarchy of being and knowledge, but rather as the very locus of the difference between being and knowledge, the fissure and finitude from which issue all things-knowledge, man himself-in their varied and incommensurable identities.

Contrary then to the caricature of "enlightenment humanism," in which it is taken as an article of faith that optical metaphors figure man's self-appointed sovereignty of the world, in "our humanism"-but what could the earlier humanisms be, that had no concept of man? - in "our humanism" man is divided against himself and all else besides: "Man, in the analytic of finitude, is a strange empirico-transcendental doublet," at once a mere finite being, a natural part of a natural world, and the "being such that knowledge will be attained in him of what renders all knowledge possible" (318). Man's vision comes into existence with his blindness: "This obscure space"-what Foucault calls the "unthought" to the modern cogito-- "is both exterior to him and indispensable to him: in one sense the shadow cast by man as he emerged in the field of knowledge; in another, the blind stain by which it is possible to know him" (326). It is the simultaneous emergence of ignorance and knowledge, blindness and vision, cogito and "unthought" that joins together, at their deepest archaeological strata, the "two great forms of analysis of our day," namely, "interpretation and formalism" (299). 
Foucault pursues this idea of man, and the human sciences, as "figuration of finitude" along several trajectories, two of which are important for our present purpose. The first concerns observational metaphors. When man is subject to the great "archaeological mutation" in which he appears "in his ambiguous position as an object of knowledge and as a subject that knows," it does not mean that we simply supersede the infamous Classical optic. Rather, the very space of observation is volatilized, internally fissured by the finitude introduced and figured by man. As a result, we get figures of instability and conceptual reversibility, an "enslaved sovereign," an "observed spectator" (312). The second trajectory concerns temporality. If man now comes to stand for an essential instability in the spatial register, both observer and observed, he similarly finds himself figuring the essential instability of historicity: "It is no longer origin that gives rise to historicity; it is historicity that, in its very fabric, makes possible the necessity of an origin that must be both internal and foreign to it" (329). Man becomes the very point of this paradoxical articulation:

the original in man is that which articulates him from the very outset upon something other than himself ... it is that which, by binding him to multiple, intersecting, mutually irreducible chronologies, scatters him through time and pinions him at the center of the duration of things. (331)

Just as man's very emergence into visibility will be figured equally by the triumph of observation and the "blind stain by which it is possible to know him," so too man will be at once the "origin" and "center" of a newly powerful historicity and that same origin's paradoxical temporal implosion, its "recession to itself" (372).

Lest we seem to have strayed too far from the historical dimension outlined by Luhmann and others, let us recall that the disturbances of vision and chronology described by Foucault are the natural outcome of the evolutionary drift away from simple "interaction." For Foucault, too, the crucial moment concerns the infolding of others' calculations in one's own, the doubling-back of representations of the social within the realm of social action:

[T] here will be no science of man unless we examine the way in which individuals or groups represent to themselves the 
partners with whom they produce or exchange, the mode in which they clarify or ignore or mask this function and the position they occupy in it, the manner in which they represent to themselves the society in which it takes place, the way in which they feel themselves integrated with it or isolated from it, dependent, subject, or free. $(352-53)$

The human sciences must take as their proper object social behavior in which the theoretical plane of representations is inextricably folded into the plane of action itself. For this reason, the thought of the social sciences, just like the social thought they study, is "no longer theoretical." As soon as such thought operates, "it offends or reconciles, attracts or repels, breaks, dissociates, unites or reunites. . . . Thought . . . is in itself an action - a perilous act" (328). Faced with this dilemma of being strung between formalization and interpretation, it is perhaps not surprising that the human sciences have become the terrain for the most vigorous epistemological debate and innovation in the past few generations. Toward the end of The Order of Things, Foucault suggests that the insistent attention to their own self-division, their own problem of finitude, has led the human sciences into what he calls an "“ana-' or 'hypoepistemological' position":

the human sciences, when they duplicate themselves, are directed not at the establishment of a formalized discourse: on the contrary, they thrust man, whom they take as their object in the area of finitude, relativity, and perspective, down into the area of the endless erosion of time. (355)

Foucault's analysis leads to a vision of the human sciences as a kind of epistemological sink-hole: unable to pass beyond an analytic of finitude but equally unable to look away, as if were we not to observe man's blind spots, there would be nothing left to observe.

In the analysis that follows, I want to unpack this idea that the human sciences occupy a "hypo-epistemological position." If we look at the grand theoretical endeavors of Lacan and Luhmann, we can see certain shared patterns of figuration, despite other very considerable, indeed irreconcilable, differences in their basic assumptions. Both Lacan and Luhmann are markedly influenced by the "linguistic turn" of the 20th century, and more 
specifically, by the promise of formalization seemingly offered by cybernetics's understanding of communication. The psychoanalyst and the sociologist must both contend, however, with the foldingover of theoretical reflection into the object of their inquiry, with the fact that, in Claude Lévi-Strauss's words, theirs are analytic endeavors in which "the observer himself is part of his observation" (29). Both Lacan and Luhmann thus start from that opening wedge between the subject and society, between "interaction" and a structural or formal understanding of social behavior; in this regard, their considerable attention to epistemological matters is dedicated to keeping these two halves from collapsing into one another. But their epistemology is self-consuming; it is not pursued to clear the field of confusions but rather occupies the entire theoretical field itself. It does this only because it is itself incomplete, with a hole in its middle. At those moments when the theoretical work of these thinkers becomes hypo-epistemological, when it confronts its own internal limit, we see reemerge the disturbances of vision and chronology that lie at the heart of the experience of finitude. Thus, these anti- or post-humanist endeavors reinstate the figure of man in the place of his erasure; man becomes, as Lacan says, "strictly equivalent to his own inexistence" or, in Foucault's famous image, a "face drawn in sand at the edge of the sea" (Foucault 387).

\section{Lacan and the Blind Gaze}

As Foucault remarks at the end of The Order of Things, psychoanalysis and ethnology "have been constituted in confrontation, in a fundamental correlation" (379). They are inversions of each other, in disputation over how to understand the "double articulation of the history of individuals upon the unconscious of culture, and of the historicity of those cultures upon the unconscious of individuals" (379). In a series of influential texts of the late forties and early fifties-most notably the "Introduction to the Work of Marcel Mauss" (1950)-Lévi-Strauss entered this confrontation with psychoanalysis, seeking to redirect inquiry away from the "American psycho-sociological school" exemplified by Ruth Benedict and Margaret Mead, and toward his emerging structural an- 
thropology (11). In making this argument in the "Introduction," Lévi-Strauss turned to a new conception of the operation of communication. To be sure, "the ethnological problem is a problem of communication" (36). But in approaching this problem one must look behind the pasteboard egos who communicate and toward the unconscious of the system, communication itself. Such a perspective no longer discloses intersubjective encounters of a more or less frustrating sort, but the "unconscious itineraries of that encounter" (36), that is, mere communicative functions producing difference in their endless turns. The seemingly insurmountable gulf of difference between subjectivities is surpassed by being functionalized; difference is not a fact of being but the fundamental operation of a system that surpasses any freeze-frame picture of its workings. This interpretive swerve leads Lévi-Strauss to invoke all the motifs so familiar to our structuralist, post-structuralist, systems-theoretical landscape. He encourages us to follow the example of Trubetskoy and Jakobson's structural linguistics, and look for the "infrastructure simpler than any [phenomenological given], to which the given owes its whole reality" (41). Mauss, too, is celebrated for construing the "notion of function following the example of algebra, implying, that is, that social values are knowable as functions of one another" (43). Ultimately, Lévi-Strauss hopes-as Lacan will ever afterward-for the "progressive mathematisation of the field" (43) of the human sciences, a hope inspired in him by the success of cybernetics's "application of mathematical reasoning to the study of phenomena of communication" (44). Lévi-Strauss theorizes the entirety of what transpires in communication as the workings of a social "symbolic."

In part through the influence of Lévi-Strauss's interest in linguistics and cybernetics, Lacan began in the fifties to articulate with more precision the relation so central to Lévi-Strauss's theorization of the elementary laws of the symbolic, namely, the relation of the individual to the larger network of social signification in which he or she is caught up. For Lacan, this takes the form of demarcating the respective dimensions of the imaginary and what he calls, with Lévi-Strauss, the "symbolic." To gain some sense of the context in which Lacan began elaborating this distinction so central to all his later thinking, one need only look carefully at his second seminar of 1954-55. Taking up the topic of "The Ego in 
the Theory of Freud and in the Technique of Psychoanalysis," the seminar was conducted parallel to a series of lectures on "Psychoanalysis and the Human Sciences," which featured presentations by (among others) Alexandre Koyré, Lévi-Strauss ("Kinship versus the Family"), Merleau-Ponty, Benveniste, and Hyppolite, and which concluded with a lecture by Lacan himself, titled "Psychoanalysis and Cybernetics, or on the nature of language." ${ }^{2}$ In focusing on the ego, Lacan is, as always, actually hammering home the necessity of moving beyond it; he is continuing his bitter quarrel with the ego-psychology then in power in the International Psychoanalytical Association. Like Lévi-Strauss, Lacan is interested in this seminar in articulating and defining theoretically a transsubjective "symbolic order" that reflects the new thinking about the formal autonomy of language and communication. But Lacan differs from Lévi-Strauss in taking as his point of departure the inadequacy of the individual's regulative function in relation to the symbolic order:

Beyond the homeostases of the ego, there exists a dimension, another current, another necessity, whose plane must be differentiated. This compulsion to return to something which has been excluded by the subject, or which never entered into it, the Verdrängt, the repressed, we cannot bring it back within the pleasure principle. If the ego as such rediscovers and recognises itself, it is because there is a beyond to the ego, an unconscious, a subject which speaks, unknown to the subject. (171)

Both Lévi-Strauss and Lacan appeal to a notion of the unconscious that seems to offer a way out of the phenomenological impasses of intersubjectivity. For Lacan, however, there is no way beyond such impasses but through; that is, the "beyond of the ego" is apprehensible only because "the ego rediscovers and recognises itself." The turns of reflection and self-consciousness are what reveal the fundamental asymmetry of the individual's relation to the larger social-symbolic world of communication in which he finds himself caught. The unconscious operating "beyond the ego" is tracked in this seminar as a "signifying insistence" (a Lacanian turn on Freud's repetition compulsion), a kind of acephalic desire that disturbs and disrupts the psychic system's fundamental inertia, its homeostatic or restitutive function $(60-61)$. On the other hand, 
the "insistence" of signification is insistent only for an ego. As Lacan demonstrates in his treatment of cybernetics, one can construct a machine that "embodies the most radical symbolic activity of man" (74), namely, the creation of a "world of symbols . . organised around the correlation of absence and presence" (300), but one will not thereby have embodied anything like an unconscious. The unconscious, as Lacan develops the concept in this seminar, names the principle of disjunction between the ego and the symbolic, and is "proper" neither to one nor the other. The fact that through "cybernetics, the symbol is embodied in an apparatus ... in a literally trans-subjective way" (304) does not lead to the conclusion that humans are in essence symbolic, and only epiphenomenally subjective-or that, as Lévi-Strauss remarks a number of times in his essay on Mauss, the symbolic system is "more real" than what carries out its functions. On the contrary, what cybernetics's embodiment "of an order which subsists in its rigour, independently of all subjectivity" (304) effectively makes visible is the rift opened up, within subjectivity as within sociality, between the imaginary and symbolic registers. This rift is the location of an unconscious that exhibits, paradoxically, both the "radical difference" between the symbolic and the imaginary registers, and the fact that "there is something in the symbolic function of human discourse that cannot be eliminated, and that is the role played in it by the imaginary" (306). Imaginary and symbolic require each other for their own articulation, but only articulate themselves as disarticulated from each other.

How does Lacan arrive at such a complex and paradoxical notion? The fact that there exists a "role played in it by the imaginary" that "cannot be eliminated" may well seem troubling to the notion of the autonomy of symbolic signification. If the symbolic order is only ever revealed-experientially, theoretically, or analytically-via the imaginary, what prevents the very autonomy of the symbolic from being simply another version of imaginary misrecognition? After all, it is precisely the function and role of the imaginary to secure the illusions of autonomy and identity out of a fundamental alienation. Lacan confronts this question directly toward the end of his lecture on cybernetics and psychoanalysis: "The issue is to know whether the symbolic exists as such, or whether the symbolic is simply the fantasy of the second degree of 
the imaginary coaptations" (306-07). He will insist in this seminar, and with increasing vehemence throughout his later work, that the symbolic does indeed "function in the real, independently of any subjectivity," because the option for him is to imagine the possibility of reducing this symbolic "beyond" to the functional dimensions of the imaginary, of dissipating its transcendent status through an ego-psychological "rectification," or "normalisation in terms of the imaginary" (307) - in other words, to capitulate to the ego-psychologists' goal of helping the patient produce a "healthy ego." But Lacan's insistence on the simultaneous inextricability and irreducibility between imaginary and symbolic registers means that he will commit himself fundamentally to observational scenarios, in which the move "beyond" the imaginary looks more like an internal crack or failure within imaginary reflection itself.

It is thus not surprising that Lacan develops his most famous parable of observation, his reading of Poe's "The Purloined Letter," in this theoretical context. In both its full text in Ecrits and its initial development in the course of the seminar, the treatment of "The Purloined Letter" concerned the way in which the symbolic "is attained most especially on the imaginary level" (177). What Poe's story stages for Lacan, both in its essential plotting concerning the letter's displacements and, just as crucially, in the interpolated commentary about the game of even and odd, is the recognition that purely imaginary observational scenarios have built into them a kind of essential fracture, a place of failure or opening, that opens onto the symbolic:

What's at issue is an essential alien [dissemblable], who is neither the supplement, nor the complement of the fellow being [semblable], who is the very image of dislocation, of the essential tearing apart of the subject. The subject passes beyond this glass in which he always sees, entangled, his own image. (177)

A page later Lacan repeats: "Under certain conditions, this imaginary relation itself reaches its own limit, and the ego fades away, dissipates, becomes disorganized, dissolves" (178). In "The Purloined Letter," the series of observers of observation (the Queen, the Minister, Dupin, etc.) believe themselves to have seen the dynamic of looks in its entirety-to have, as it were, the imaginary, 
intersubjective scenario fully laid out before them. The observers of observation are not wrong; they correctly assess what they see in the room. Lacan's point is rather that we have here a parable of the imaginary relation reaching its own point of dissolution, in which the observational vantage cannot stay merely observational, but finds itself caught up, precipitated, into a symbolic circuit of action. It is this position in the symbolic circuit, defined by the relation to the letter, that most profoundly confers identity on the story's players, and not any one character's adequate or inadequate reflective understanding.

The appearance of the symbolic dimension beyond the imaginary is, then, a problem of action and of time. To demonstrate this more clearly, we will refer to an earlier essay, the essential elements of which reappear at the end of the 1955 seminar, where the essay is described as illustrating precisely the importance of "distinguishing the imaginary from the symbolic" (287). It is a text originally written in 1945, titled "Logical Time and the Assertion of Anticipated Certitude: A New Sophism." I will quote John Forrester's translation of the scenario, which can be found in his excellent commentary on Lacan's theories of temporality. A "prison governor" must free one of three prisoners and will allow their "lot to be determined by a test":

There are three of you here. Here are five discs which differ only in their colour: three are white, and two are black. Without letting you know which of them I have chosen, I am going to fasten one of these discs between each of your shoulders, that is to say, out of the bearer's direct vision; all possibility of his being able to catch sight of it indirectly is also excluded by the absence here of any means of looking at himself.

Thereafter you will be free to consider at your leisure your companions and their respective discs, without being allowed, of course, to communicate to each other the fruits of your inspection ... [T] he first who can deduce his own colour shall profit from the measure of liberty of which we dispose. (Forrester 178-79)

All three prisoners are then given white discs. "After they have pondered a certain time, the three subjects together make a few steps toward the door, arriving there abreast." They each give the following reasoning: 
I am a white, here is how I know it. Given that my companions were whites, I thought that, if I were a black, each of them would have been able to make the following inference: "If I were also a black, the other, immediately realising from this that he is a white, would have left straight away; therefore I am not a black." And the two others would have left together, convinced of being whites. If they stayed put, it is because I am a white like them. (179)

Forrester asserts that this sophism serves Lacan in his later work as "the model for all the relations between the subject, a set of signifiers, and temporality" (179-80). From our perspective, its importance lies in its presentation of the modulation, through a distinctive temporality, between imaginary and symbolic registers. The strictly reflective, imaginary methods at the disposal of the prisoners can lead to a knowledge of the symbolic structure in which they are caught only by virtue of an odd temporal jump between what Lacan calls the "time for understanding"- "directly articulated upon the time of meditation of the other," as Forrester writesand what he calls the "moment for concluding." Out of a strict intersubjectivity, in other words, emerges a dimension beyond, one in which certitude cannot be had through a mere reflective assessement, but can only be retroactively verified by an action that is already presented as being too late: "From hesitating, a pulsation leads immediately to being too late. This precipitation is not simply a contingent effect of the dramatic situation; the subject must make haste, because if he does not, and the two others beat him to it, then he will no longer be sure that he is not black" (181).

Commenting on this sophism 10 years later in the seminar, Lacan claims that it demonstrates that a "relation to time peculiar to the human being" governs this movement of haste beyond the intersubjective: "there is a third dimension of time which [cybernetic machines] are not party to, ... which is neither belatedness, nor being in advance, but haste. .. . That is where speech is to be found, and where language, which has all the time in the world, is not" (Seminar, Book II 291). And in the lecture on cybernetics, he makes the point again:

With a machine, whatever doesn't come on time simply falls by the wayside and makes no claims on anything. This is not true for man, the scansion is alive, and whatever doesn't come 
on time remains in suspense. That is what is involved in repression. (307-8)

When Lacan writes, in the seminar, that "the subject [of the sophism] holds in his hands the very articulation by which the truth he sifts out is inseparable from the very action which attests to it" (289), we have in fact a double, paradoxical articulation. The subject can "know" something only by acting in haste, by a "precipitation in the act" (289), a precipitation that is always ahead of the verification it brings. If it is in some sense true that the subject "holds in his hands" the articulation necessary to arrive at the truth, then, it could just as easily be said that the subject's "precipitation in the act" just is the articulation between the truth arrived at in the imaginary "time for comprehending" and its manifestation in the symbolic "moment for concluding." This temporal lurch-like stepping onto the moving platform of a carousel-is that whereby the subject modulates, perhaps agonizingly, but always in the anxiety of "haste," between he who articulates signifiers and he who merely embodies the articulation of signifiers. The vantage from which it seems that the subject manipulates signifiers (white, black) to represent another subject (himself), suddenly flips over into a temporalized movement in which the "signifier ... represents the subject for another signifer" ("Subversion of the Subject" 317).

Lacan here imagines man at a point of radical temporal disjunction, a "precipitation in the act," a tumbling over or lurching movement. Man does not articulate here, but is shown to be articulated temporally. Thus, the "precipitation in the act"-even as it, in anticipating, moves beyond whatever certitude the reflective ego can attain, even as it presents the surpassing of the self-does not move beyond identity but rather bores into its most secret mechanism. A seemingly semantic pattern can help draw out this connection between imaginary and symbolic identity. In the essay on "logical time," Lacan describes a process of "decanting" by which the "I"- the " $j e$ " of the conclusive assertion (which is presented definitively only in the act of making for the door)-is drawn off from the earlier moments of reflection, each with their appropriate "subject" forms. ${ }^{3}$ This final identity-marker, the one bound up with the anticipated certitude of the act, is 
isolated by a beat of logical time with the other, that is with the relation of reciprocity. This movement of the logical genesis of the je, by means of a decanting of its own time, is parallel to its psychological birth. In the same way that ... the psychological "I" disengages itself from an undetermined specular transitivism ... the "I" in question here is defined by the subjectivizing of a competition with the other in the function of logical time. (208)

Given this explicit parallel between the "logical genesis" of the $j e$ and its "psychological birth," it is perhaps not surprising that the same odd figure of "decanting" should emerge later in Lacan's treatment of the construction of identity-in-difference that is the mirror stage. Samuel Weber has directed attention to what he takes to be a crucial addition to the theorization of the mirror stage, a revision articulated by Lacan in his paper on Daniel Lagache's "Psychoanalysis and the Structure of the Personality." "The context," writes Weber, "is defined by the question of the Other (capital O): that is, by the function of alterity or heterogeneity in discourse" (116). (It is, of course, precisely this question that animates the entirety of the second seminar. Jacques-Alain Miller draws attention to this trajectory by titling the third section of the text "Beyond the Imaginary, the Symbolic; or, From the Little to the Big Other.") Weber notes a slight revision in the canonical presentation of the child's recognition and jubilation before the mirror:

In contrast to Lagache's "personalistic" interpretation of Freudian doctrine, Lacan stresses the impersonal structure "of this Other, where discourse is situated"; such alterity, he continues, reaches to "the purest moment of the mirror relation." What is this "purest moment"? Lacan locates it [and here Weber translates the passage to be found in Ecrits 678)] in the gesture by which the child at the mirror, turning around to the person carrying it, appeals with a look to the witness who decants, by verifying it, the recognition of the image from the jubilant assumption, in which, to be sure, $i t$ [such recognition] already was. (116)

Let us clarify what is at issue here. Weber understands the "verification" being provided by the "witness" as intervening 
between two moments - recognition and jubilation - that had earlier seemed coeval:

In the original version of the text of the mirror stage, the effect of the reflection upon the child seemed to result from its recognition of the image as its own likeness. ... In the later essay, recognition is no longer enough; instead, in its stead, there appears the anxiety which causes the child to twist back, turning around, and in this gesture, to seek the confirming look of another ... [T] he jubilant reaction does not relieve the child from having to seek something like an acknowledgement of the other. In this sense, recognition is no longer a process organized around two poles: child and mirror image, subject and object. Instead, it emerges as a triadic relation in which the acknowledgement emanates not from the self-identical ego, but from the "person who carries it," that is, from the place of the Other. (118)

We could say, perhaps, that the jubilant assumption of identity in the mirror stage, in the imaginary, was a bit hasty, a bit precipitate, because it now seems to need to be verified. But recall that the lurch into the symbolic in the essay on logical time was exactly coincident with this precipitation into action and that this was also the verification of the truth that could be certified in no other way for the merely reflective ego. The temporal suspension at work in this imbrication of the symbolic within the imaginary construction of identity is once again on Lacan's mind. The "event" in question here is the very assumption and recognition of identity, whose status is forever suspended in a temporal distention by the "tertiary presence" of the symbolic.

But what about this mysterious "witness" who appears in this essay, who verifies, who decants, and who, as Lacan insists, "owes nothing to the anecdotal figure who incarnates it" ("Remarque" 678)? Weber remarks that this Other "can in essence be determined neither as an individual, nor as a social function, nor as a subject in general. Indeed, it is nothing more than the differentiality upon which discourse depends" (119). The status of the "witness" as pure differentiality would seem to accord well to its temporal paradoxicality, its coming to be only in no longer being there. This mysterious Lacanian "witness" who stands behind the 
games of mirror-identity and ego-construction is precisely the guarantor of that game in constituting its exception and undoing. This is a witness who verifies by disappearing, whose temporal fading as pure differentiality attests to a symbolic order which is beyond time. Such would seem to be the implication of a particularly metaphysical moment towards the end of the second seminar:

The wager lies at the heart of any radical question bearing on symbolic thought. Everything comes back to to be or not to be, to the choice between what will or won't come out, to the primordial couple of plus or minus. But presence as absence connotes possible absence or presence. As soon as the subject comes himself to be, he owes it to a certain non-being on which he raises his being. And if he isn't, if he isn't something, he obviously bears witness to some kind of absence, but he will always remain purveyor of this absence. I mean that he will bear the burden of its proof for lack of being capable of proving the presence. (192)

There is a structure of debt here and of witnessing that issues ineluctably from the "primordial couple of plus or minus," presence or absence, being or non-being. But this structure is asymmetrical, out of whack; the second terms-minus, absence, non-being: in short, differentiality-always have the upper hand. If the subject comes to be, "he owes it to a certain non-being on which he raises his being." In notable contrast, the "structure of that tertiary presence" of the witness "owes nothing to the anecdotal figure that incarnates it." This witness guarantees, stands surety for, the game that plays out the inevitable collapse of all witnessing. In the "wager" that starts with pure differentiality-the wager of a postontological social thought founded on the nonfoundation of a signifying order with no positive terms-the game is secured, the structural order guaranteed and verified, by the very collapse or evanscence of the terms or figures who serve as its "human support" (192). Negation is primal, because the "primordial couple" is such only through its own self-cancelling.

At the same time, however, we may well question this erection of a debt-free symbolic realm, one that owes nothing to its human supports, its only theater. For, as Lacan himself insists, this order 
of non-being shares one essential feature with its human support: an insistent desire. Here are the closing words of the seminar: "The symbolic order is simultaneously non-being and insisting to be, that is what Freud has in mind when he talks about the death instinct as being what is most fundamental-a symbolic order in travail, in the process of coming, insisting on being realised" (326). The paradox of this relation between being and non-being is what realizes itself in the strange image of the witness or blind gaze in Lacan's thought. For it is precisely by demanding that the subject "verify" its (self)recognition through an appeal to a "witness" who fades away before one's eyes and who thus images the "essential tearing apart of the subject"-it is precisely in giving over to the human his own self-superseding in signification that non-being comes to be. The big Other, which has no ontological status, paradoxically comes to be, realizes itself, in the movement whereby the human recreates himself in the image of the blind gaze to which, he can't help feeling, he owes everything.

When Foucault writes that the social order and the figure of man are co-created on the ground of a radical finitude, he could well be describing Lacan's construction of the symbolic. Just as Foucault writes of the "blind stain by which it is possible to know" man, Lacan talks of the symbolic as "like an image in the mirror, but of a different order." This order is a kind of monstrous beyond of the imaginary, a beyond of the elaborate optics defining the positionality of self and other. "It isn't for nothing that Odysseus pierces the eye of the Cyclop," Lacan continues gnomically (185). The symbolic can only appear through a mutation process within the imaginary, in which vision and reflection is first inflated to the monstrous proportions of the singular Cyclopean eye, and then blinded, passed beyond, negated. Such a negation, such a recognition of the stain in the mirror, which is also already a passing beyond it, is perhaps the ultimate "precipitation in the act," the temporal lurch bestowing identity. Lacan comments that it is only by blinding the Cyclops, creating of him a blind gaze, that the subject can open communication. This symbolic realm of communication is the home of negation and radical finitude, in which man attains a paradoxical freedom and identity in knowing himself to be, like Odysseus, "No Man." 


\section{Luhmann and the Constructed Observer}

Niklas Luhmann's systems-theoretical sociology does not underestimate the immense creativity of Odysseus's negating prowess. ${ }^{4}$ Luhmann's work is a career-long celebration of the fecundating power of distinctions, and reading his work can at times be a dizzying enterprise, as his terms and oppositions reproduce in a process of discursive mitosis. His is also one of the more extended and impressive explorations of the power of systems to operate paradoxically and self-referentially, which makes it hardly surprising that his arguments rarely proceed in a linear fashion, but rather by a reiterative process. Luhmann's oeuvre is vast and complex, even for someone who reads him in translation; there can be, therefore, no question of surveying the entire range and import of that work. ${ }^{5}$ I want instead merely to present enough of his theoretical edifice to situate an interrogation of a particularly insistent distinction in his theory, namely the unconditional divorce between what he calls psychic systems and social systems.

Like Lévi-Strauss and Lacan, though perhaps with even more vehemence, Luhmann wishes to avoid the lures of any theoretical understanding based on models of the subject of reflection: "The subjectivist problem was to state and to show how it is possible by means of introspection - that is by the passage to the self-reference of one's own consciousness-to form judgments about the world of others" ("Cognitive Program" 66). It is not possible, asserts Luhmann; and indeed the realization of this limit was both the result of, and the further spur for, the differentiation of society and interaction in modernity-that is, the empirical and theoretical divide between a sociality understood on the model of a face-to-face intersubjectivity (which is, after all, finally the model of subjectivity) and one thought of as operating according to its own nonsubjective operations. A fundamental consequence of discarding subjectivist approaches to sociality is the recognition, by now canonical, that there is no vantage-even the theoretical one of "absolute knowledge"-from which one can perceive and know a reality as absolutely external to oneself. The optics of self-reflection, inaugurated for modernity in Cartesian dualism, must be replaced by a functionalized understanding of primal difference. Thus, we get the 
familiar view of a signifying order beyond representationalism or realism:

Cognition is neither the copying nor the mapping nor the representation of an external world in a system. Cognition is the realization of combinatorial gains on the basis of the differentiation of a system that is closed off from its environment (but nonetheless "contained" in that environment). ("Cognitive Program” 69)

The notion of a "system closed off from its environment" is fundamental to Luhmann's thought. Following both systems theory and, more crucially, the theory of autopoiesis of Maturana and Varela, the notion of closure here put forward needs to be understood in all its equivocalness. A system effects closure not through a radical indifference to its environment, a pure unaffectedness; rather, being operationally closed means that changes in the environment can function only as "triggers" for the system and take effect in the system only when, and if, they are coded by the internal system as systemic (and not environmental). Such a view of the system/environment relation emphasizes autonomy and closure; it repudiates strict causal interpretations (where, for instance, an environmental factor can unilaterally "cause" a change in a given system) and it disallows input-output models (wherein a system might be seen to "process" environmental factors). Most importantly for our argument, it is fundamentally opposed to any view of the relation between system and environment based on modelling, or likeness; there can be no ground on which two systems can recognize themselves as "like each other," since there is no system that does not reproduce itself save by closure, by differentiation: "The function of the boundaries [of any system] is not to pave the way out of the system but to secure discontinuity" (66).

Like Lacan's irreducible function of misrecognition, this view of system closure is bracingly anti-humanist when considered from the vantage of any psychology:

By this means [the theory of autopoietic systemic closure], the significance of psychological epistemologies is considerably reduced, but relieved at the same time of the unreasonable expectation that they should provide more than individual- 
psychological knowledge. There is no such thing as "man," no one has ever seen him and if one is interested in the system of observation that organizes its distinctions by means of this word or concept one discovers the communication-system called society. There are now approximately 5 billion psychological systems. It has to be asked which of these 5 billion is intended when a theory of knowledge employing a psychological reference system relates concepts such as observation and cognition to consciousness. (78)

The same point is made in slightly different terms in a recent article specifically dealing with the relation between psychic and social systems:

Everyone knows, of course, that the word "human being" is not a human being. We must also learn that there is nothing in the unity of an object that corresponds to the word. Words such as "human being," "soul," "person," "subject," and "individual" are nothing more than what they effect in communication. They are cognitive operators insofar as they enable the calculation of continued communication.... The unity that they represent owes its existence to communication. ("How Can the Mind Participate?" 387)

The names for identity do not refer outside the system in which they operate. That is, there is no "real" unity of human identity corresponding to the words "soul," etc.; there is only what communication can do with this word. The system-reference for such signifiers is not, in other words, the psychic system, but the social system, for it is only the social system, according to Luhmann, that reproduces itself by means of communication; the psychic system reproduces itself as an autopoiesis of consciousness ("Autopoiesis" 2). In the communication system that simply is society, "subjects are spoken of to define the self-referential foundation of the cognitions of the mind" ("How Can the Mind Participate?" 387). Consciousness, as an autopoietic system, may have a kind of paradoxical and self-referential unity, but it has nothing to do with the unity of a word like "person," which is merely a "cognitive operator" and thus "owes its existence to communication." In short, Luhmann agrees with Lacan on this question: the signifier represents the 
subject for another signifier. It is only in order to keep communication going that the unities of "person," etc. are fabricated. Because psychic systems are wholly environmental for social systems, the latter have to fabricate their own discursive unities-the notorious ideologemes of humanism: "soul," "person," "subject," "individual," and "human being."

But why? Why should communication systems - that is, social systems-need to create this figment of individual identity? This question touches on one of the most difficult issues in Luhmann's theoretical enterprise, the description of the mode of relation between psychic systems and social systems. For it turns out that they are not only, or not merely, environmental for one another, despite Luhmann's insistence that they remain so in the theoretical last instance. Their relation is more complicated. In what Luhmann concedes is a less than satisfying expression, he claims that psychic and social systems "interpenetrate." He explains:

\begin{abstract}
"Interpenetration" does not refer to a comprehensive system of coordination or to an operative process of exchange (something that would require being able to talk about inputs and outputs in this sense). "Interpenetration" can only mean: the unity and complexity (as opposed to specific conditions and operations) of the one is given a function within the system of the other. ("How Can the Mind Participate?" 386; see also "Individuality" 117)
\end{abstract}

The name for the interpenetration of psychic and social systems when seen from the psychic system is "socialization" (386). "Communications systems," on the other hand, "experience interpenetration by considering the personal dynamics of humans in their physical and mental (including the mind) dimensions" (386). But it is puzzling that a strictly nonpsychic system of communication could be in a position to "consider . . . personal dynamics," much less "experience" anything at all. As with Lacan's mysterious characterization of the symbolic dimension "insisting" on being, we return here, in Luhmann's theory, to a discursive, signifying system that in essence opposes and excludes the psychic dimension, and yet somehow is endowed with expressive desires, insistence, abilities to "experience." What does the communication system's "consideration of personal dynamics" look like? 
Answering this question leads us back to the motif we have been examining throughout this essay-namely, the oddly central status of the figure of the observer in theories of nonsubjective signifying orders. In order to comprehend Luhmann's complex answer to this question, we need to widen the perspective somewhat. In an early programmatic essay titled "Meaning as Sociology's Basic Concept," one does not find such emphasis on the radical disjunction between psychic and social systems. The influence of Husserl and Parsons on Luhmann's thinking is more pronounced at this point in his career, and it is Parsons, indeed, who bequeaths to Luhmann the problem of "double contingency": "All experience or action that is oriented to others is doubly contingent in that it does not depend solely on me, but also on the Other, who I must regard as an alter ego, i.e., as just as free and unpredictable as I am" ("Meaning" 45). In this early essay, the transition from such intersubjective scenarios to social structures is considerably more integrated than it will later become. It is still possible for Luhmann to write that, although "social structures do not take the form of expectations about behavior"- that would be to return to a notion of sociology as concerned with the elemental unit of "action" rather than "meaning," precisely the notion being disputed in this essay - they can be understood as the maintenance of a certain "level of reflexive expectation," or "expectations about expectations" (45). There would seem, then, to be a crucial role for a kind of intersubjective reflection in the creation of social structures.

At the same time, however, "meaning" is already operating in this early essay as the conceptual wedge between psyche and sociality, opening up the possibility, more and more vigorously pursued through the next 20 years, of emptying out this reflection of any subjective reference.$^{6}$ Habermas has criticized Luhmann's theory as a philosophy of the subject wholly emptied out of subjectivist depths:

Systems theory has to remove from the "self" of the relationto-self all connotations of an identity of self-consiousness established by synthetic performances. Self-relatedness is characteristic of individual systemic accomplishments in their mode of operation; but no center in which the system as a whole is 
made present to itself and knows itself in the form of selfconsciousness issues from these punctual relations-to-self. In this way, the concept of reflexivity is separated from consciousness. But then an equivalent is needed for the conscious substrate of the self-relatedness that is distinctive of the level of sociocultural life. As an emergent attainment corresponding to consciousness, Luhmann introduces a peculiar concept of "meaning." (369)

Whether or not one considers Luhmann's concept of meaning to be "peculiar," it is surely right to recognize that what allows for "the concept of reflexivity [to be] separated from consciousness" is Luhmann's theorization of meaning and, more specifically, "communication." The theoretical extrication of reflexivity from consciousness by means of a kind of discourse theory entails, however, as it did for Lacan, the rhetorical intrication of the figures of observation with the development of the idea of communication. What the figure of observation offers, for this paradigm, is the possibility (perhaps even the inevitability) of a vantage on the operation of the communication system, of seeing the code as code.

This helps to explain why one sees observers everywhere in Luhmann's thought. In "The Cognitive Program of Constructivism," his most thoroughgoing epistemological treatment of this theme, one comes across sentences that sound like abstract synopses of Poe's "The Purloined Letter":

Constructivism describes the observation of observation that concentrates on how the observed observer observes. This constructivist turn makes possible a qualitative change, a radical transformation, in the style of recursive observation, since by this means one can also observe what and how an observed observer is unable to observe. (73)

In part, this predilection for the language of observation is due to Luhmann's incorporation of the vocabulary of second-order cybernetics. At the same time, we should note that Luhmann's desire to ground a notion of reflexivity beyond the subject leads him to emphasize not observation as such, but rather its constitutive limit. Luhmann's metaphor of observation is, as it were, a self-cancelling figure, and thus very like Lacan's in this regard. For the entire 
point of observation is that it always proceeds by way of a fundamental blindness: "The 'blind spot' of each observation, the distinction it employs at the moment, is at the same time its guarantee of a world" (70). Later in the same essay, he makes the point more fully:

For cognition, only what serves in a given case as a distinction is a guarantee of reality, an equivalent of reality. One could say more precisely: The source of distinction's guaranteeing reality lies in its own operative unity. It is, however, precisely as this unity that the distinction cannot be observed-except by means of another distinction which then assumes the function of guarantor of reality. Another way of expressing this is to say that the operation emerges simultaneously with the world which as a result remains cognitively unapproachable to the operation. (76)

Every observation involves making a distinction, the background operative unity of which is that observation's enabling blind spot, at once constituting the system's operational closure and bringing forth a world. It would seem that one needs the figure and errancy of observation in order to serve as cover for the more profoundly creative power of blindness.

We can already see, I think, how Luhmann's use of this figure echoes that of Lacan, for we have here an anti-intuitionist, antihumanist account of the construction of meaning systems that constitutes itself on the back of a blinded observer. In reading Luhmann on the difference between psychic and social systems, it often feels that Habermas's characterization is apt:

The flow of official documents among administrative authorities and the monadically encapsulated consciousness of a Robinson Crusoe provide the guiding images for the conceptual uncoupling of the social and psychic systems, according to which the one is supposedly based solely on communication and the other solely on consciousness. (378)

But Luhmann's account of the way psychic systems participate in communication is more complex than this characterization, for in 
fact the two systems "interpenetrate" in a mutually interfering way reminiscent of the symbiotic antagonism between Lacan's symbolic and imaginary registers.

Thus, in recent essays, Luhmann has returned to the question of the construction of an observer in the kind of intersubjective scenarios he has been treating with suspicion for some time. Given his own idea of the operational closure of psychic systems, he asks,

why would an observer observe another observer as observer, as another psychical system? Why isn't the other system seen simply as a normal object in the external world, that is, why isn't it simply observed directly instead of as a pathway for the observing of its observing? ("Cognitive Program" 79)

From the perspective of the psychic system, Luhmann is asking, how does it happen that another psychic system can be imagined as not merely an object? Luhmann rejects psychological accounts in which "it is usually assumed that this is made possible by a sudden, intuitive analogy: the other is experienced as an alter ego, as operating like another I" (79); he dismisses as well Maturana's attempt to deal with the issue from a biological perspective. Writing with a not uncharacteristic disciplinary partisanship, Luhmann puts forward a "third theoretical suggestion (which draws on sociology, since psychology and biology have not sufficed)," namely that "the other observer is a necessary consequence of communication" (79).

What Luhmann describes here is a kind of trickery by which the system of communication creates the illusion for a psychic system (whose "observation" here is indeed neurophysiological, that is, a matter of perception and consciousness) that there is another unity-another observer - with whom it can communicate:

Within the communication system we call society, it is conventional to assume that humans can communicate. Even clever analysts have been fooled by this convention. It is relatively easy to see that this statement is false and that it can only function as a convention and only within communication. The convention is necessary because communication necessarily addresses its operations to those who are required to continue communication. ("How Can the Mind Participate?" 371) 
A communication system needs psychic systems to reproduce itself, but it can only use psychic systems if they are mystified as to their own ability to communicate. Those who are "required" to continue communication are, paradoxically, those who precisely cannot do so, namely the psychic systems called "humans." We get a sense of the stringency of this requirement in Luhmann's characterization of the mind's "participation" in communication: "it is sufficient for the communication process to understand that the mind, virtually helpless, must participate" ("How Can the Mind Participate?" 376) in the fabrication of this unity of an "other" with whom to communicate. And indeed, in a conception reminiscent of Lacan's elaborate schemas of the optical delusion of the imaginary, Luhmann here relies on the idea of "fascination," presenting the mind the way explorers and conquistadors used to describe the natives, as fascinated by shiny objects: "Language and script fascinate and preoccupy the mind and thereby secure its participation" (376); these technologies of communication constitute "special experiential objects that are either extraordinary or fascinating" (375). It is in this way that communication leads the psychic system into a "detour": "The detour via communication, the participation in a completely different operating system, and the attractiveness of the constitutive difference of this system are all critical for the constitution of an alter ego" (emphasis added) - that is, for the critical, though illusory, "convention" that there exists an other with whom I can, as psychic system, communicate (385).

It is not entirely clear what this "attractiveness of the constitutive difference" between psychic and social system would be. Even as Luhmann puts forth an account of how psychic systems are lured into imagining and constructing a sameness, he also sees at work a kind of alluring differentiation. It turns out, indeed, that psychic systems are crucially engaged in distinguishing and thereby introduce what could be characterized as a rhetorical dimension to the interpenetration of psychic and social systems. "Communication is only possible," writes Luhmann, "when an observer is able, in his sphere of perception, to distinguish between the act of communication and information, that is, to understand communicative acts as the conveying of information (and not simply as behavior)" ("Cognitive Program" 79). What psychic systems are really required to do is distinguish-and that this dis- 
tinguishing is a matter of the psychic system is emphasized by Luhmann's reference to perception-between constative and performative dimensions of language. Communication cannot continue if it does not reproduce itself by means of the distinction between information and utterance-or, as the same distinction is translated elsewhere, between "facts" and "behaviors." In other words, communication is self-divided; although not itself anything psychic, much less bodily, it nonetheless needs such psyches and bodies to operate, and what it needs them to do is constantly to renew their own distinction from the communication system, by indicating the difference between information and utterance. Communication systems are not merely interpenetrated by psychic systems, they are incomplete without them, but paradoxically they can only effect closure, complete themselves operationally, by having their own incompletion or dividedness rearticulated. Communication reproduces itself by luring psychic systems into attributing certain communications to other psychic systems as their "actions" ("Autopoiesis" 6-7). In doing this, communication both refers to its own constitutive distinction between information and utterance, between hetero-reference and self-reference, and it fabricates and presupposes the synthesis of these distinctions in the attribution of action. Humans, psychic systems, are communication's alibis, its constantly rearticulated "presupposition" of synthesis.

This presupposition of synthesis is an operative element that cannot be reduced further. When Luhmann describes the autopoiesis of social systems in communication, he appeals to such an "undecomposable unit" upon which, at every moment, in every linkage or articulation, the system depends. This unit, for communication, is the "synthesis of information, utterance and understanding" ("Autopoiesis" 4), a synthesis that is "operative": "As an operating unit it is undecomposable, doing its autopoietic work only as an element in the system" (4). At the same time, because we are here dealing with a meaning-based system that can "reenter" its own constitutive distinction from the environment within its system, communication can only "observe" itself, "re-enter" or recur, by disarticulating this very distinction:

It is forced by its own structure to separate and to recombine hetero-referentiality and self-referentiality. Referring to itself, the process has to distinguish information and utterance and 
to indicate which side of the distinction is supposed to serve as the base for further reference. Therefore, self-reference is nothing but reference to this distinction between heteroreference and self-reference. (4)

That is, communication's self-reference and psychic self-reference (here considered as the perception of the difference between information and utterance considered above) are one and the same, considered from the vantage of their results. Just as much as psychic systems, the self-reference of the communication system only takes place by the insistent disarticulation of selves and reference, bodies and language, or in Luhmann's terms, psychic and social systems. But with each new disarticulation, the fiction of the synthesis of self- and hetero-reference must be "presupposed" anew. The working of self-reference, its essential differentiating movement, requires at every moment a mirage of identity from which to distinguish itself, a synthesis to cancel and disarticulate. Every observation proceeds only on the back of the presupposition of a prior, "blind" operation. (Luhmann asserts unambiguously that "operations of the mind and of communication proceed blindly" ["How Can the Mind Participate?" 382].) The figure of observation requires then, for its very existence, the concept of blind operation. In the "construction of an observer," of the blind, helpless, fascinated gaze of a deluded psychic system, the communication system secures its own operational closure by imagining it has successfully located its own environment. And the same holds for those perceiving psychic systems forever differentiating themselves through reference to the distinction between communicative behaviors and mere information.

What Luhmann's theory allows us to say is that meaningsystems require the alibi of identity in order to keep going. This identity is an always presupposed, because always already undone, synthesis "blind" to its own internal rupture or constitutive difference. In pointing out this rupture and this blindness, "observation" creates the necessary next fiction of "operation." The problem is that this "observation" cannot but presuppose the "operation," and in positing a blinded observer-say, a psychic system deluded about its ability to communicate-the observing system merely regards itself in the mirror without recognizing that fact. Insofar as both psychic and social are essentially meaning- 
based systems with the ability to "re-enter" their own constitutive distinction, their "interpenetration" is precisely their simultaneous operation, as each observes its self-distinction and thus presupposes the necessary operation in the other. They are inextricably joined in their inability to proceed without constantly disarticulating one from another, self- from hetero-reference. Their essential unity lies in their paradoxical operational commitment to "closure." Because "identity" is a problem for them, because they cannot achieve identity otherwise than differentially, theirs is a symbiotic antagonism; each functions as the operation for the other's observation, the alibi of an environment for the other's system.

But in a swerve that should no longer be surprising, these observational paradoxes are reformulated, or recoded, by Luhmann as temporal predicaments. ${ }^{7}$ The structure I have just been describing, in which the "continuing dissolution of the system becomes a necessary cause of its autopoietic reproduction" ("Autopoeisis" 9), is described in temporal terms when Luhmann writes that "conscious systems and social systems have to produce their own decay," that they must "produce their basic elements . . not as short-term states but as events that vanish as soon as they appear" (9). These events serve as another version of the "presupposed synthesis" allowing for autopoiesis, and thus retain a maximum of paradoxicality:

Events can be identified and observed, anticipated and remembered only as such a difference. Their identity is difference. Their presence is a copresence of the before and the thereafter. They have to present time within time and have to reconstruct time within a shifting presence. ("Autopoiesis" 11)

Such a presentation of "time within time" cannot do otherwise than solder the gap between synchrony and diachrony; it is the very inextricability of the psychic and the social, articulated in meaning, an inextricability whose "identity is difference," that dictates such a temporal suspension of "time within time." For the same reason, the spatial predicament bequeathed by the epistemological concerns of the human sciences - the predicament of observers both outside and inside that which is observed-is charac- 
terized by the observation of observation. Formally speaking, observation and the event are versions of each other; just as observation introduces a wedge between the operation "before" (the one being distinguished, rendered visible), and the one to come "thereafter" (that is, the one inaugurated anew with the observing distinction, but which has no present existence for that observation), so the event self-consumes in coming to be, is only its unenduring distinctiveness vis-à-vis its past and its future. If the observer appears as his own blindness, that can also be described as the event which appears in its own surpassing. The interpenetration between the spatial (observation) and the temporal (event) descriptions is frankly recognized by Luhmann: "If autopoiesis bases itself on events, a description of the system needs not only one, but two dichotomies: the dichotomy of system and environment and the dichotomy of event and situation" (10).

I reintroduce the term "interpenetration" in the last sentence advisedly. For it seems to me that here, with the recoding of observational paradoxes as temporal ones, we reach the furthest limit of Luhmann's theoretical endeavor. The system for which such a temporal recoding is most important, even urgent, is not the psychic system, but rather the social system of communication intent on processing information. Jean-François Lyotard has recently offered some intriguing commentary on what he characterizes as the accelerating expansion of a cosmic Leibnizian monad, a mathesis universalis governed by the "compulsion to communicate and to secure the communicability of anything at all" (62). For Lyotard, as for Luhmann, the efficiency of the communication system depends to a very large extent on the ability to present time within time, to process and manage the event:

The importance of the technologies constructed around electronics and information processing resides in the fact that they make the programming and control of memorizing, i.e. the synthesis of different times in one time, less dependent on the conditions of life on earth. It is very probable that among the material complexes we know, the human brain is the most capable of producing complexity in its turn, as the production of the new technologies proves. And as such, it also remains the supreme agency for controlling these technologies. 
And yet its survival requires that it be fed by a body, which in turn can only survive in the conditions of life on earth, or a simulacrum of those conditions. I think that one of the essential objectives of research today is to overcome the obstacle that the body places in the way of the development of communicational technologies, i.e. the new extended memory. (62)

When Luhmann characterizes the paradoxes of the social system's autopoiesis as a "built-in requirement of discontinuity and newness" answering the system's "necessity to handle and process information" ("Autopoiesis" 10), he describes in his own terms what Lyotard calls the "compulsion to communicate." Social systems as communication processors handle information; they reproduce themselves via the constant rearticulation of the distinction between information and utterance, fact and behavior, themselves and psychic systems. Such a compulsion, we can see, cannot proceed otherwise than by constantly trying to overcome the obstacle of the body, and all the noninformational facets of meaning adhering to psychic and social behavior.

I will return now to Foucault, who described two elements of the analytic of finitude within which we still operate. One was a visual or observational metaphor: "the blind stain" by which it is possible to know man as wedded to what he cannot see. The other was essentially temporal: as the locus of a temporal origin "always in recession to itself." From the perspective of the psychic system, the interpenetration of psychic and social-the expression each gives of the finitude of the other-is most powerfully expressed in the first, observational, metaphor. It is very hard not to place bodies and psyches at the root of all talk of observation. When the temporal paradox comes to the fore-as it does occasionally in Luhmann and Lyotard, for instance-I think we can see the other face of this interpenetration. For it is from the vantage of a truly supra-individual communication system that man's finitude-his very psycho-corporeal embeddedness - is best expressed not as the limit of vision, but as a temporal pulse. More and more, I suspect, we will watch man confront his own finitude not in the form of the mote in his eye, but as the moment that passes in the merest blink. More and more, the human seems less an observer coupled 
to his own blindness than a switch or relay who can be "on" only because it can just as well be "off." Our metaphors of communication may be giving way to communication's metaphors of us.

\section{Notes}

1. See Hacking. Jacques Derrida has also taken up the interrelation between questions of human identity, conjecture, and probability in "Psyche: Inventions of the Other."

2. The list of lectures is given in Seminar, Book II 294.

3. The first of these forms would be the "impersonal subject," which is expressed in the "one" of the "one knows that ...," and which "gives merely the general form of the noetic subject" ("Le Temps logique" 207). "The second, which is expressed in 'the two whites' who must recognize themselves 'in each other,' introduces the form of the other as such, that is as pure reciprocity" (208).

4. See "The Paradoxy of Observing Systems" in a forthcoming issue of this journal. Speaking of the endless way in which, with each observation, a new unmarked space is at once "severed" and (re)-created, Luhmann comments drily: "We resist the temptation to call this creation."

5. For a clear and up-to-date summary of Luhmann's theory, see "Systems Theory According to Niklas Luhmann" in this issue.

6. As Habermas has remarked, this theoretical itinerary, precisely in its hostility to the philosophical tradition of the subject of reflection, situates itself as much in that very tradition as anywhere else:

It is not so much the disciplinary tradition of social theory from Comte to Parsons that Luhmann tries to connect up with, as the history of problems associated with the philosophy of the subject from Kant to Husserl. His systems theory does not, say, lead sociology onto the secure path of science; rather it presents itself as the successor to an abandoned philosophy. (368)

7. For a subtle consideration of the issue of temporality in Luhmann's work, especially as it relates to deconstructive thought on time, see Cornell.

\section{Works Cited}

Cornell, Drucilla. "The Relevance of Time to the Relation Between the Philosophy of the Limit and Systems Theory: The Call to Judicial Responsibility." The Philosophy of the Limit. New York: Routledge, 1992. 116-54.

Derrida, Jacques. "Psyche: Inventions of the Other." Trans. Catherine Porter. Reading de Man Reading. Ed. Lindsay Waters and Wlad Godzich. Minneapolis: U of Minnesota P, 1989. 25-65.

Forrester, John. "Dead on Time: Lacan's Theory of Temporality." The Seductions of Psychoanalysis: Freud, Lacan and Derrida. Cambridge: Cambridge UP, 1990. 168-218.

Foucault, Michel. The Order of Things: An Archaeology of the Human Sciences. Trans. Alan Sheridan. New York: Random, 1970. 
Habermas, Jürgen. "Excursus on Luhmann's Appropriation of the Philosophy of the Subject through Systems Theory. The Philosophical Discourse of Modernity: Twelve Lectures. Trans. Frederick G. Lawrence. Cambridge: MIT P, 1987. 36885.

Hacking, Ian. The Taming of Chance. Cambridge: Cambridge UP, 1990.

Heims, Steve Joshua. Constructing a Social Science for Postwar America: The Cybernetics Group, 1946-1953. Cambridge: MIT P, 1991.

Herbert, Christopher. Culture and Anomie: Ethnographic Imagination in the Nineteenth Century. Chicago: U of Chicago P, 1991.

Lacan, Jacques. "De nos antécédents." Ecrits. Paris: Editions du Seuil, 1966. 65-72.

—. "Le séminaire sur 'La Lettre volée'." Ecrits. Paris: Editions du Seuil, 1966. $11-61$.

. "Le Temps logique et l'assertion de certitude anticipée: Un noveau sophisme." Ecrits. Paris: Editions du Seuil, 1966. 197-213.

- "Remarque sur le rapport de Daniel Lagache: Psychanalyse et structure de la personnalité." Ecrits. Paris: Editions du Seuil, 1966. 647-84.

- The Seminar of Jacques Lacan, Book II: The Ego in Freud's Theory and in the Technique of Psychoanalysis, 1954-55. Ed. Jacques-Alain Miller. Trans. Sylvana Tomaselli. New York: Norton, 1988.

- "Subversion of the Subject and the Dialectic of Desire in the Freudian Unconscious." Ecrits: A Selection. Trans. Alan Sheridan. New York: Norton, 1977. 292-325.

Lévi-Strauss, Claude. "Introduction to the Work of Marcel Mauss." Trans. Felicity Baker. London: Routledge, 1987.

Luhmann, Niklas. "The Autopoiesis of Social Systems." Essays on Self-Reference. New York: Columbia UP, 1990. 1-20.

- "The Cognitive Program of Constructivism and a Reality that Remains Unknown." Selforganization: Portrait of a Scientific Revolution. Ed. Wolfgang Krohn, Günter Küppers, and Helga Nowotny. Dordrecht: Kluwer, 1990. 6485.

"The Evolutionary Differentiation between Society and Interaction." The Micro-Macro Link. Ed. Jeffrey C. Alexander, Bernhard Giesen, Richard Münch, and Neil J. Smelser. Berkeley: U of California P, 1987. 112-31.

- "How Can the Mind Participate in Communication?" Materialities of Communication. Ed. Hans Ulrich Gumbrecht and K. Ludwig Pfeiffer. Trans. William Whobrey. Stanford: Stanford UP, 1994. 371-87.

- "The Individuality of the Individual: Historical Meanings and Contemporary Problems.” Essays on Self-Reference. New York: Columbia UP, 1990. 107-22.

- "Meaning as Sociology's Basic Concept." Essays on Self Reference. New York: Columbia UP, 1990. 21-79.

Lyotard, Jean-François. "Time Today." The Inhuman: Reflections on Time. Trans. Geoffrey Bennington and Rachel Bowlby. Stanford: Stanford UP, 1991. 58-77.

Weber, Samuel. Return to Freud: Jacques Lacan's Dislocation of Psychoanalysis. Cambridge: Cambridge UP, 1991.

Wiener, Norbert. Cybernetics, or Control and Comunication in the Animal and the Machine. 2nd ed. Cambridge: MIT P, 1948. 